\title{
Overexpression of engulfment and cell motility 1 promotes cell invasion and migration of hepatocellular carcinoma
}

\author{
JIARUI JIANG，GUOQING LIU，XIONGYING MIAO, SONGWEN HUA and DEWU ZHONG \\ Department of Hepatobiliary Surgery, The Second Xiangya Hospital, Central \\ South University, Changsha, Hunan 410011, P.R. China
}

Received January 17, 2011; Accepted March 15, 2011

DOI: $10.3892 /$ etm.2011.229

\begin{abstract}
Engulfment and cell motility 1 (Elmo1) has been linked to the invasive phenotype of glioma cells. The use of Elmo1 inhibitors is currently being evaluated in hepato-cellular carcinoma (HCC), but the molecular mechanisms of their therapeutic effect have yet to be determined. Elmol expression in HCC tissue samples from 131 cases and in 5 HCC cell lines was determined by immunohistochemistry, quantitative RT-PCR and Western blotting. To functionally characterize Elmo1 in HCC, Elmo1 expression in the HCCLM3 cell line was blocked by siRNA. Cell migration was measured by wound healing and transwell migration assays in vitro. Elmol overexpression was significantly correlated with cell invasion and the poor prognosis of HCC. Elmo1-siRNA-treated HCCLM3 cells demonstrated a reduction in cell migration. The present study demonstrated for the first time that the suppression of Elmo1 expression inhibits cell invasion in HCC.
\end{abstract}

\section{Introduction}

Hepatocellular carcinoma (HCC) is one of the most common malignancies worldwide, particularly in China. HCC is the second leading cause of cancer-related death among males (1). Although advances have been made in the diagnosis and treatment of HCC, the long-term outcome for patients with $\mathrm{HCC}$ is still extremely poor due to its high recurrence and metastasis rate (2). The five-year recurrence rate in HCC is as high as $50-60 \%$ (3). Thus, the ability to predict individual risk of recurrence and subsequent prognosis is critical to guide surgical and chemotherapeutic treatment (4-7). Therefore, it is necessary to investigate the molecular alterations correlated with the recurrence or metastasis of HCC. The recurrence and metastasis of HCC is a complex process involving various factors at each step $(8,9)$.

Correspondence to: Dr DeWu Zhong, Department of Hepatobiliary Surgery, The Second Xiangya Hospital, Central South University, 139 Renmin Road, Changsha, Hunan 410011, P.R. China

E-mail: zhdewu1218@gmail.com

Key words: engulfment and cell motility 1, hepatocellular carcinoma, invasion, metastasis, cell migration
Cell migration is one characteristic of highly aggressive metastatic cancer cells (10), and is one of the most important steps in HCC invasion and metastasis (11-13). Cell migration is highly regulated by spatial and temporal changes in the actin cytoskeleton which are essential for many physiological and pathological processes, including cancer cell invasion. Rac1, a member of the Rho GTPase family, is a key regulator of actin cytoskeletal dynamics and relays signals from various stimuli such as growth factors, cytokines and adhesion molecules to downstream effectors modulating cell migration and invasion (14). Notably, Rac1 has been shown to promote HCC cell migration (15-17). Dock180 is known to be the main target of signal adaptor protein Crk and acts as a guanine-nucleotide exchange factor for small GTPase Rac1. Studies in Caenorhabditis elegans and Drosophila reveal that Dock180 homologues modulate various functions including phagocytosis, cell migration and actin cytoskeletal organization through the activation of Rac1 (18). Dock180 facilitates nucleotide exchange on Racl through its unconventional Docker GEF domain (19), but requires binding to engulfment and cell motility 1 (Elmo1) to achieve GDP/GTP exchange on Rac (20). As a result, the Dock180 family of proteins has been suggested to function as an upstream regulator of the small GTPase Rac. The best characterized Rac activation mediated by the Dock family is through the Dock180-Elmol complex.

Although studies with experimental models have indicated an important role of Elmo1 in cell invasion and migration in human glioma and ovarian cancer cell lines (21), the clinical evidence of the role of Elmol in human HCC is limited. Therefore, in the present study, we evaluated the expression of Elmol in HCC tissues and analyzed its correlation with clinicopathological characteristics and the prognosis of HCC. Elmo1 expression was investigated in HepG2 cells with low metastatic potential and HCCLM3 cells with high metastatic potential by Western blotting. Knockdown of Elmol in HCCLM3 cells caused a reduction in cell migration and invasion. In addition, cell migration and invasion was measured by in vitro wound healing and transwell migration assays.

\section{Materials and methods}

Patients and specimens. Prior informed consent was obtained from the patients for the collection of liver specimens in accordance with the guidelines of The Second Xiangya 
Hospital of Central South University. The study protocols were approved by the Ethics Committee of the Central South University, Changsha, Hunan, China. HCC specimens were collected from 131 patients who underwent hepatic resection for HCC at the Department of Surgery, The Second Xiangya Hospital of Central South University from October 2005 to November 2008. The patients did not receive transcatheter arterial chemoembolism therapy or any local ablative therapy. The sample included 115 males and 16 females with a median age of 49 years (range 21-79). From these 131 HCC cases, fresh specimens of matched adjacent non-tumorous tissues (ANTTs) were collected from 32 cases. The samples were immediately frozen in liquid nitrogen and subsequently stored at $-80^{\circ} \mathrm{C}$ for reverse transcription-polymerase chain reaction (qRT-PCR) and Western blot analysis. Five normal liver samples were obtained from 5 patients with liver cavernous hemoangioma as controls. The specimens were embedded in paraffin and stained by H\&E. The diagnoses of the patients were confirmed by histopathology Histopathological examination was conducted in a blinded manner.

Real-time reverse transcription-polymerase chain reaction. qRT-PCR was performed as described previously (22). The primers for Elmol were as follows: forward, 5'-TGCCACA AAGTGCTGGAGATG-3'; reverse, 5'-ACGGACAGGCTCAG GTGATTC-3'. GAPDH expression was determined as a control using primers: forward, 5'-GCACCGTCAAGGCTGAGAAC-3'; reverse, 5'-TGGTGAAGACGCCAGTGGA-3'. The real-time PCR reaction was carried out on an ABI 7500 thermal cycler (Applied Biosystems) using SYBR ${ }^{\circledR}$ Green I chemistry. The PCR cycling parameters were as follows: 50 cycles at $95^{\circ} \mathrm{C}$ for $5 \mathrm{sec}$ and at $60^{\circ} \mathrm{C}$ for $20 \mathrm{sec}$. The results were analyzed using the $2^{-\Delta \mathrm{Ct}}$ method according to the formula: $\Delta \mathrm{Ct}=\mathrm{Ct}_{\mathrm{Elmol}}-\mathrm{Ct}_{\mathrm{GAPDH}}$.

SDS-PAGE and Western blot analysis. Tissues from HCC samples, ANTTs and the cell lines were lysed with buffer containing $50 \mathrm{mM}$ Tris- $\mathrm{HCl}, \mathrm{pH} 7.3,150 \mathrm{mM} \mathrm{NaCl}$, $2 \%$ NP-40, 0.5\% deoxycholate, 2 mM EDTA, 2 mM NaF, and $1 \%$ protease inhibitor cocktail (Pierce, Rockford, IL, USA). Total protein $(100 \mu \mathrm{g})$ was separated by SDS-PAGE and transferred to polyvinylidene difluoride filters (PVDF) (Millipore, Danvers, MA, USA). Membranes were blocked in $5 \mathrm{mg} / \mathrm{ml} \mathrm{milk}$, incubated with the goat polyclonal anti-Elmo1 (1:400; Abcam UK), anti-Rac1 and anti-fibronectin (1:500; Santa Cruz Biotechnology, Santa Cruz, CA, USA) antibodies. HRP-conjugated mouse anti-goat IgG (1:2000; KPL, Gaithersburg, MD, USA) was used as the secondary antibody. The membrane was extensively washed, and the proteins were detected with the Enhanced SuperSignal West Duro chemiluminescence system (Pierce). $\beta$-actin (1:300; Sigma-Aldrich, St. Louis, MO, USA) was used as a reference probe.

Immunohistochemistry and follow-up. Paraffin-embedded tissues were sectioned into serial $4-\mu \mathrm{m}$ slices and stained with hematoxylin and eosin (H\&E). In brief, after deparaffinization and rehydration, endogenous peroxidase was blocked with methanol containing $0.3 \%$ hydrogen peroxide for $30 \mathrm{~min}$ and microwave-pretreated in EDTA buffer (1 mM, $\mathrm{pH} 8.0)$ for $10 \mathrm{~min}$ for antigen retrieval. The concentration of goat polyclonal anti-human Elmo1 antibody was 1:300. Immunostaining for Elmol was carried out with the streptavidin-peroxidase system (Zhongshan Golden Bridge Biotechnology, Beijing, China). Nuclei were lightly counterstained with hematoxylin. Negative controls were treated with phosphate-buffered saline (0.01 M, pH 7.2) instead of the antibodies. The Elmol protein level in each section was scored on a scale of 0 to $3+$ to delineate low expression $(0$ or $1+)$ or high expression $(2+$ or $3+)$. Scoring was performed by two independent investigators blinded to the clinical and follow-up data.

Patient follow-up was carried out through written correspondence or telephone contact. The rate of follow-up was $92.0 \%$. A total of 131 patients were followed up post-operatively for 30-1300 days, with a median follow-up time of 460 days. The diagnosis of recurrence and metastasis was based on postoperative imaging, serum AFP levels or re-operative resection. Overall survival was calculated from the date of surgery to the date of death or last follow-up. Disease-free survival was calculated from the date of surgery to the date of recurrence, metastasis, death or last follow-up. To determine factors influencing survival after hepatic resection, the following 8 conventional clinicopathological variables were assessed in all 131 HCC cases: gender, age, liver cirrhosis, AFP concentration, tumor size, Edmondson-Steiner grade and vein invasion.

Cell lines and cell culture. The HCC HepG2 and HCCLM3 cell lines, normal liver L-02 cells and 293T retroviral packaging cells were purchased from the Cell Institute, Shanghai, China. These cell lines were cultured in high glucose Dulbecco's modified Eagle's media (Gibco-BRL, Gaithersburg, MD, USA) supplemented with $10 \%$ fetal bovine serum (HyClone Laboratories Inc., Logan, UT, USA) and maintained in $5 \% \mathrm{CO}_{2}$ at $37^{\circ} \mathrm{C}$.

Plasmids and transfection. Empty vector pSuper.retro. neo-GFP was purchased from Invitrogen Inc. Two different Elmol small interfering RNA (siRNA) DNA oligonucleotides were designed using OligoEngine RNAi design software. siRNA for human Elmol targeting 19 nucleotides of the human Elmol transcript (nucleotides 2921-2949, 5'-TGAGGACTGATGTGGTAGA-3') and siRNA targeting another region of the human Elmo1 transcript (nucleotides 12561298, 5'-TCCGCATTTAGTGGACAGG-3') were designed. According to the insert sequence of the Mission Non-Target siRNA control vector(5'-CAACAAGATGAAGAGCACCAA-3'; Sigma), a control non-target siRNA was designed using two different Elmol siRNAs and one non-target siRNA segment subcloned in the pSuper-GFP vector, respectively. 293T retroviral packaging cells, used for the production of amphotropic virus, were transfected with the relevant pSuper retroviral expression plasmid (Invitrogen, USA) at a confluence of $70 \%$ using Lipofectamine 2000 (Invitrogen) according to the manufacturer's instructions. Clones expressing the retrovirus at $1 \times 10^{5}$ colony-forming $\mathrm{U} / \mathrm{ml}$ were selected for subsequent experiments. Multiple rounds of infection, which increase the number of infected cells as well as the number of copies per cell, were carried out during the transfection of the HCCLM3 cells. Briefly, medium containing the retrovirus was added to the cells supplied with polybrene $(5 \mu \mathrm{g} / \mathrm{ml})$ for $12 \mathrm{~h}$; after a 12 -h rest by replacing the medium with fresh medium, the retrovirus was added again. This double infection resulted in a $60-70 \%$ transfection efficiency. 
A

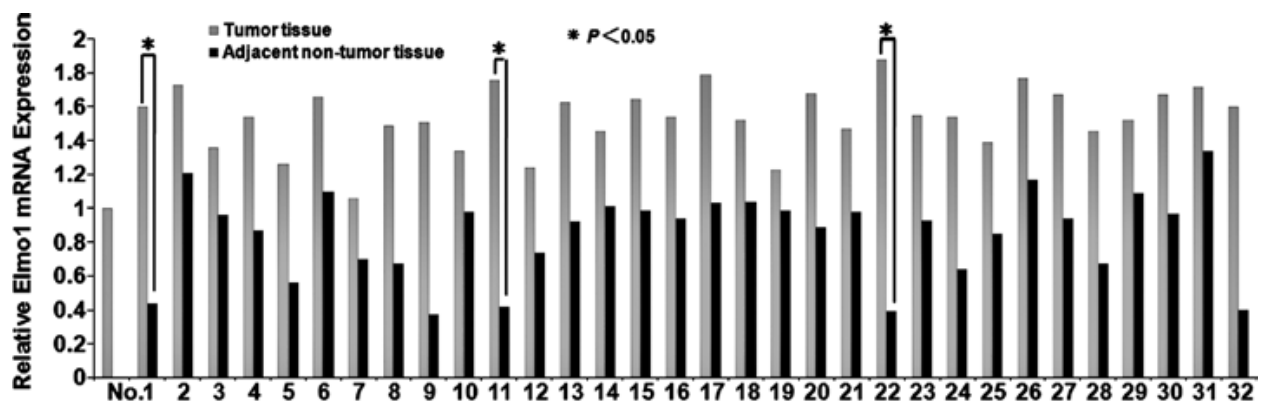

B

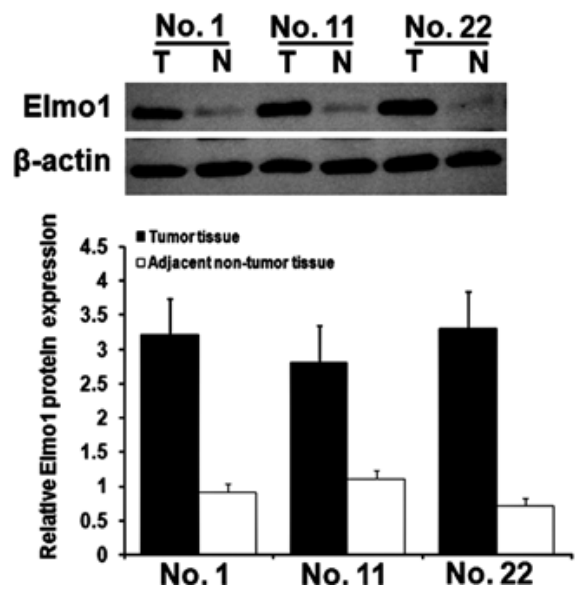

C

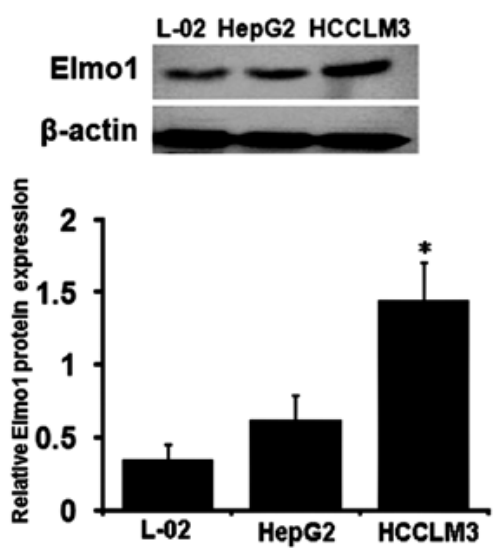

Figure 1. Expression levels of Elmol mRNA and protein in the HCC tissues and the adjacent non-tumor tissues (ANTTs). (A) Expression levels of Elmol mRNA in the 32 cases of HCC tissues and ANTTs. (B) Expression levels of Elmol protein in the HCC tissues (T) and ANTTs (N), respectively. Expression of Elmo1 mRNA and protein in the HCC tissues was significantly higher than that in the ANTTs $(\mathrm{P}<0.05)$. (C) Western blot analysis of Elmo1 protein expression was performed in the HepG2 and HCCLM3 HCC cell lines and in L-02 cells as a control. $\beta$-actin was used as the internal control for equal loading. The results indicated that the HCCLM3 cell line may be an ideal target for Elmo1 suppression.

Migration and invasion assays. For the migration assay, HCCLM3 cells $\left(1 \times 10^{6}\right)$ were seeded on $6-\mathrm{cm}$ plates coated with $10 \mu \mathrm{g} / \mathrm{ml}$ type I collagen. The cells were incubated for $24 \mathrm{~h}$, and the monolayer was then disrupted with a cell scraper (1.2-mm diameter). Images were captured at 0 and $24 \mathrm{~h}$ under a phase contrast microscope (Nikon ELWD 0.3). Experiments were carried out in triplicate, and four fields for each plate were assessed. For the invasion assay, a transwell plate with an $8-\mu \mathrm{m}$ diameter pore membrane (Costar) was coated with $200 \mu \mathrm{g} / \mathrm{ml}$ Matrigel and incubated overnight. Twenty-thousand HCCLM3 cells were seeded into the upper chamber of the transwell, and the lower chamber was filled with $0.8 \mathrm{ml}$ DMEM supplemented with $0.5 \% \mathrm{FCS}$ to induce chemotaxis. After $24 \mathrm{~h}$ of incubation at $37^{\circ} \mathrm{C}$, the cells were fixed in methanol and stained with H\&E. The number of cells that invaded through the pores to the lower surface of the filter was counted under a microscope. Three invasion chambers were used per condition. The values obtained were calculated by averaging the total number of cells from three filters.

Statistical analysis. Analysis was conducted using SPSS 11.5 software (SPSS Inc., Chicago, IL, USA). Quantitative values were presented as the mean $\pm \mathrm{SD}$ or the median (range). The independent t-test was used to compare Elmol mRNA and protein expression in HCC and ANTT samples. Potential relationships between Elmol expression and clinicopathological variables were assessed by analysis of variance (ANOVA). Survival curves were plotted using the Kaplan-Meier method and analyzed using the log-rank test. In addition, the univariate and multivariate Cox proportional hazards regression model was used to identify independent risk factors for survival. All tests were two-tailed, and $\mathrm{P}<0.05$ was considered to indicate statistical significance.

\section{Results}

Expression of Elmol $m R N A$ and protein in HCC tissues and cell lines. The Elmol mRNA levels in the HCC tissues were significantly higher than those in the ANTTs, as determined by qRT-PCR analysis (Fig. 1A). The t-test showed that the expression of Elmol mRNA in the HCC tissues was significantly higher than that in the ANTTs $(8.3 \pm 0.8$ vs. $1.7 \pm 0.7$; $\mathrm{P}<0.05)$. The same 32 paired specimens were assessed by Western bloting (Fig. 1B). Consistent with the mRNA expression, the Elmol protein levels in the HCC tissues were significantly higher than those in the paired ANTTs $(1.42 \pm 0.32$ vs. $0.43 \pm 0.11 ; \mathrm{P}<0.05)$. However, there were no differences between the mRNA and protein levels the ANTTs and the normal liver tissues (data not shown). Correlations between Elmol mRNA and protein expression with clinicopathological characteristics of HCC were investigated, and Elmol expression was significantly related to vein invasion of HCC $(\mathrm{P}<0.05)$. However, no correlation was found between Elmol expression and the other clinicopathological features of the HCC cases $(\mathrm{P}>0.05)$ (Table I). To determine the correlation between Elmol expression and HCC metastasis, 
Table I. Elmo1 mRNA and protein expression levels in relation to clinicopathologic parameters of 32 cases of HCC.

\begin{tabular}{|c|c|c|c|c|c|}
\hline Clinicopathologic variables & No. & mRNA & P-value & Protein & P-value \\
\hline \multicolumn{6}{|l|}{ Gender } \\
\hline Male & 30 & $1.35 \pm 0.52$ & & $0.92 \pm 0.24$ & \\
\hline Female & 2 & $1.04 \pm 0.13$ & 0.608 & $0.89 \pm 0.12$ & 0.415 \\
\hline \multicolumn{6}{|l|}{ Age } \\
\hline$\leq 60$ years & 26 & $1.28 \pm 0.48$ & & $0.90 \pm 0.21$ & \\
\hline$>60$ years & 6 & $1.51 \pm 0.61$ & 0.528 & $0.92 \pm 0.32$ & 0.758 \\
\hline \multicolumn{6}{|l|}{ Liver cirrhosis } \\
\hline Absence & 6 & $1.44 \pm 0.55$ & & $1.03 \pm 0.22$ & \\
\hline Presence & 26 & $1.29 \pm 0.49$ & 0.393 & $0.87 \pm 0.22$ & 0.423 \\
\hline \multicolumn{6}{|l|}{ Tumor size } \\
\hline$\leq 5 \mathrm{~cm}$ & 6 & $1.11 \pm 0.34$ & & $0.75 \pm 0.14$ & \\
\hline$>5 \mathrm{~cm}$ & 26 & $1.36 \pm 0.51$ & 0.332 & $0.93 \pm 0.23$ & 0.236 \\
\hline \multicolumn{6}{|l|}{ Tumor nodules } \\
\hline Multiple ( $\geq 2)$ & 20 & $1.47 \pm 0.52$ & & $1.00 \pm 0.20$ & \\
\hline Solitary & 12 & $1.06 \pm 0.31$ & 0.164 & $0.73 \pm 0.15$ & 0.153 \\
\hline \multicolumn{6}{|l|}{ Cell differentiation } \\
\hline I-II & 15 & $1.12 \pm 0.35$ & & $0.79 \pm 0.17$ & \\
\hline III-IV & 17 & $1.53 \pm 0.52$ & 0.059 & $1.01 \pm 0.21$ & 0.061 \\
\hline \multicolumn{6}{|l|}{ Vein invasion } \\
\hline Absence & 17 & $1.08 \pm 0.37$ & & $0.74 \pm 0.22$ & \\
\hline Presence & 15 & $1.55 \pm 0.53$ & $0.004^{\mathrm{a}}$ & $1.09 \pm 0.26$ & $0.006^{\mathrm{a}}$ \\
\hline
\end{tabular}

${ }^{\mathrm{a}} \mathrm{P}<0.05$

the expression of Elmo1 was determined in the HCCLM3 and HepG2 cells and the normal liver L-02 cell line as the control using qRT-PCR and Western blotting. As shown in Fig. 1C, the expression of Elmol protein in HCCLM3 was significantly higher than that in the HepG2 cells $(1.67 \pm 0.11 \mathrm{vs}$. $1.06 \pm 0.02 ; \mathrm{P}<0.05)$. Collectively, the results are in agreement with previously findings that Elmol expression is correlated with metastatic potential in HCC, and that the HCCLM3 cell line may be a suitable target for Elmol suppression.

Correlation of Elmol expression with the prognosis of HCC. Immunohistochemical staining was carried out in all 131 paired HCC sample. Among the cases, $85.7 \%$ displayed positive staining primarily in the cytoplasm of the cells within the tumor tissues (Fig. 2A), while $22.9 \%$ exhibited positive staining in the non-tumor tissues $(\mathrm{P}<0.05)$ (Fig. 2B). We further examined whether positive Elmol expression was correlated with the prognosis of HCC. Low expression of Elmol was correlated with a longer median survival time compared with high expression. The overall survival time between the patients with low or high Elmol expression levels was significantly different (1010 vs. 597 days; $\mathrm{P}=0.013$ ) (Fig. 2D), as was the median overall disease-free survival time between the patients with low or high Elmo1 levels (690 vs. 921 days; $\mathrm{P}=0.002$, Fig. 2C). To assess whether the expression level of Elmol is an independent prognostic factor for the survival of HCC patients, univariate and multivariate Cox regression analyses were used to identify factors that may predict survival after hepatic resection. Univariate Cox regression analysis indicated that the
Elmol expression level, tumor size, Edmondson-Steiner grade, Child-Pugh classification, serum AFP level, liver cirrhosis and vein invasion were all significantly associated with survival. Using multivariate Cox regression analysis, the Elmo1 expression level (HR 3.32; $\mathrm{P}=0.001)$ and microscopic vein invasion (HR 2.95; $\mathrm{P}=0.02$ ) were found to be independent prognostic factors of survival (Table II).

Elmol affects HCCLM3 invasion and migration. siRNA treatment was employed to inhibit the expression of Elmo1 in HCCLM3 cells with high metastatic potential. As shown in Fig. 3A, the candidate sequence inhibited the protein expression of Elmo1 by $>60 \%$. After a 3-week selection in medium supplemented with G418, the HCCLM3 cell line Elmol-siRNA was successfully contructed, which stably expressed decreased Elmo1. We first investigated the effect of Elmol on the invasion and migration of HCCLM3 cells. As shown in Fig. 3B, Elmo1-siRNA cells exhibited an $85 \%$ decrease in wound healing ability compared to the control cells $(\mathrm{P}<0.05)$, suggesting a role for Elmol in the migration of HCCLM3 cells. To substantiate this observation, a Matrigel invasion assay in transwell culture chambers was carried out to determine the effect of Elmol on the in vitro invasion of HCCLM3 cells. As shown in Fig. 3C, the proportion of Elmo1siRNA cells that passed through the Matrigel was only $13 \%$ compared with that of the control cells $(\mathrm{P}<0.05)$. Together, these results support a critical role for Elmol in the invasion of HCCLM3 cells. Meanwhile, the reduced expression of Rac1 and increased expression of fibronectin were also noted 
A

C
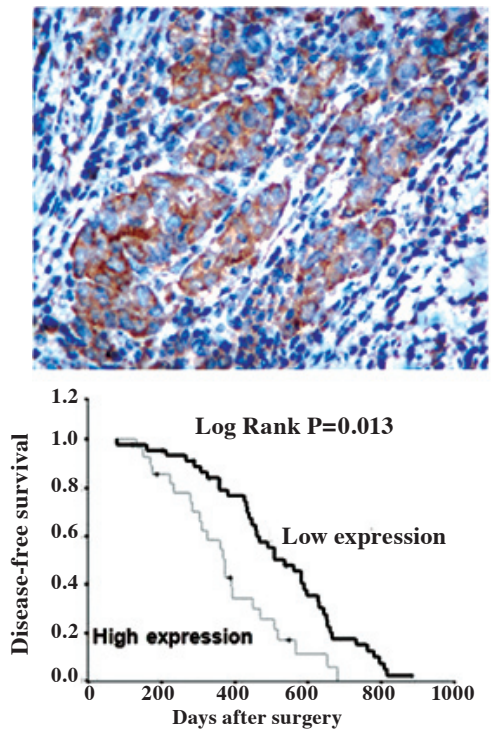
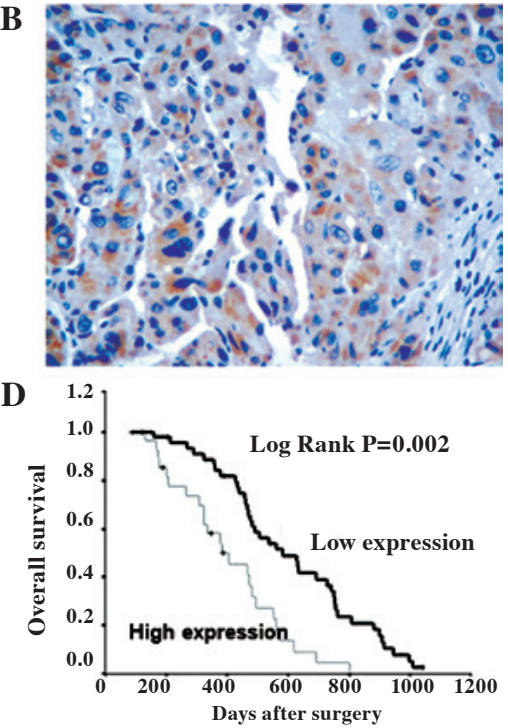

Figure 2. Immunohistochemical detection of the protein expression of Elmol in HCC tissue and adjacent non-tumorous tissue (ANTT). (A) Positive staining for Elmo1 was noted in HCC tissue (original magnification, x400). (B) Weak staining for Elmol was noted in the pericarcinomatous liver tissue (original magnification, x400). Estimated (C) disease-free survival and (D) overall survival according to the expression of Elmo1 in 131 cases of HCC by the Kaplan-Meier method. Based on the results of immunohistochemical staining, the expression of Elmol was classified as low expression $\left(0\right.$ or $\left.1^{+} ; \mathrm{n}=52\right)$ and high expression $\left(2^{+}\right.$or $\left.3^{+} ; n=79\right)$. The log-rank test shows that HCC patients with low Elmol expression had a longer median overall survival time and median disease-free survival time than patients with high expression.

A
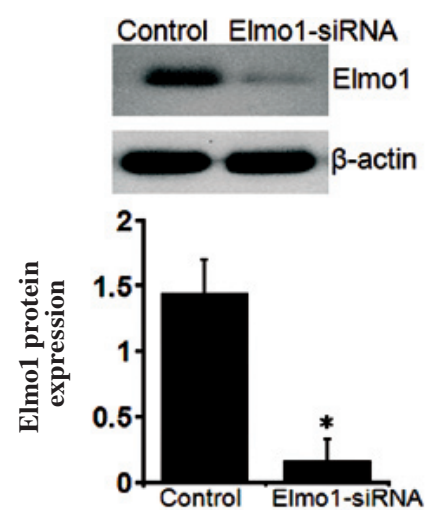

C
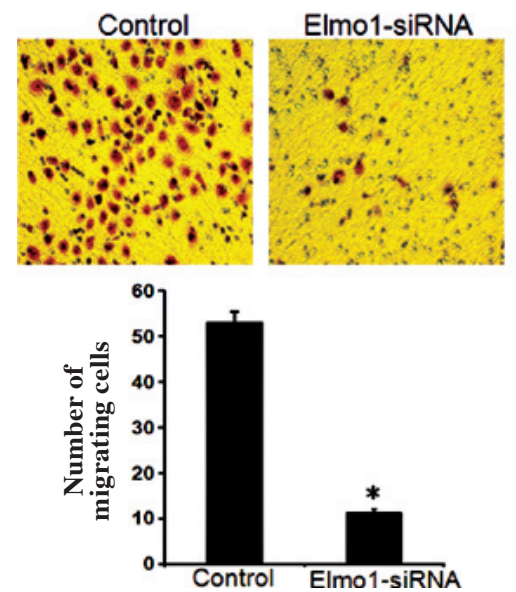
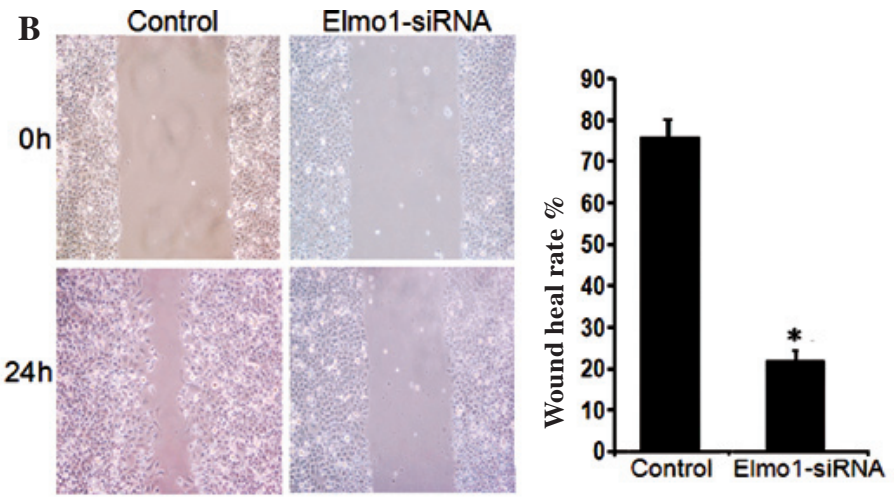

D

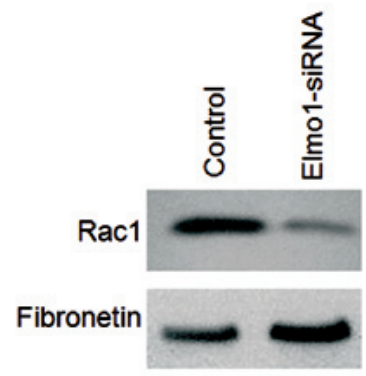

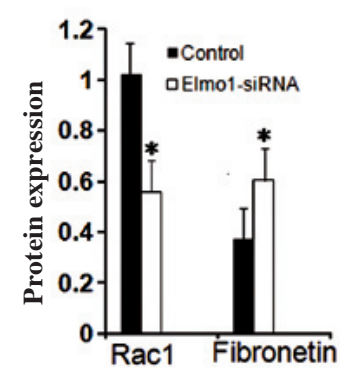

Figure 3. Effect of gene silencing using Elmo1 siRNA on HCC cell migration and invasion. (A) After treatment of HCCLM3 cells with Elmo1 siRNA, Elmo1 protein expression in the normal and Elmo1-siRNA HCCLM3 cells was analyzed by SDS-PAGE and immunoblotting. $\beta$-actin expression levels were used to verify the equal loading of cellular protein. (B) After treatment with Elmo1 siRNA, a cell migration assay was performed. HCCLM3 cells (1x10 $\left.{ }^{6}\right)$ were seeded on $6-\mathrm{cm}$ plates coated with $10 \mu \mathrm{g} / \mathrm{ml}$ type I collagen. The cells were incubated for $24 \mathrm{~h}$ and the monolayer was disrupted with a cell scraper $(1.2-\mathrm{mm}$ diameter), then images were captured at 0 and $24 \mathrm{~h}$ under a phase contrast microscope. Experiments were carried out in triplicate, and four fields of each plate were assessed. (C) For the Matrigel invasion assay, HCCLM3 cells $\left(2 \times 10^{5}\right)$ were seeded into the upper chamber of the Transwell, and the lower chamber was filled with $0.8 \mathrm{ml} \mathrm{NIH}-3 \mathrm{~T} 3$ conditioned medium to induce chemotaxis. After $24 \mathrm{~h}$ of incubation at $37^{\circ} \mathrm{C}$, the cells that invaded through the pores to the lower surface of the filter were counted under a microscope. Three invasion chambers were used per condition. The values obtained were calculated by averaging the total number of cells from three filters, and statistical analysis was performed using the Student's t-test. The data are expressed as the mean \pm SD of at least three independent studies. (D) The reduced expression of Rac1 and increased expression of fibronectin were also noted in the Elmo1-siRNA HCCLM3 cells, indicating that Elmol expression may be involved in cell adhesion to the extracellular matrix and cell migration. 
Table II. Multivariate Cox analysis for the prediction of survival factors of HCC.

Multivariable analysis

\begin{tabular}{|c|c|c|c|}
\hline \multirow{2}{*}{ Variables } & \multirow[b]{2}{*}{ No. } & \\
\hline & & Relative risk $(95 \% \mathrm{CI})$ & P-value \\
\hline \multicolumn{4}{|l|}{ Age (years) } \\
\hline$<60$ & 106 & 1 & \\
\hline$\geq 60$ & 25 & $1.042(1.008-1.077)$ & 0.280 \\
\hline \multicolumn{4}{|l|}{ Cirrhosis } \\
\hline Absence & 56 & 1 & \\
\hline Presence & 75 & $1.25(0.83-1.52)$ & 0.330 \\
\hline \multicolumn{4}{|l|}{ Tumor size } \\
\hline$<5 \mathrm{~cm}$ & 56 & 1 & \\
\hline$\geq 5 \mathrm{~cm}$ & 75 & $1.22(0.76-1.82)$ & 0.380 \\
\hline \multicolumn{4}{|l|}{ Serum AFP } \\
\hline$\leq 20 \mathrm{ng} / \mathrm{ml}$ & 47 & 1 & \\
\hline$>20 \mathrm{ng} / \mathrm{ml}$ & 84 & $0.86(0.44-1.16)$ & 0.490 \\
\hline \multicolumn{4}{|c|}{ Cell differentiation ${ }^{\mathrm{a}}$} \\
\hline I-II & 50 & 1 & \\
\hline III-IV & 81 & $1.05(0.94-1.13)$ & 0.190 \\
\hline \multicolumn{4}{|c|}{ Microscopic venous invasion } \\
\hline Absence & 87 & 1 & \\
\hline Presence & 44 & $2.95(2.03-3.78)$ & $0.020^{\mathrm{b}}$ \\
\hline \multicolumn{4}{|c|}{ Elmo1 expression } \\
\hline Low & 52 & 1 & \\
\hline High & 79 & $3.32(2.09-4.36)$ & $0.001^{\mathrm{c}}$ \\
\hline
\end{tabular}

CI, confidence interval. ${ }^{\mathrm{a} E d m o n d s o n ~ g r a d i n g . ~}{ }^{\mathrm{b}} \mathrm{P}<0.05$; ${ }^{\mathrm{c}} \mathrm{P}<0.01$.

in the Elmo1-siRNA HCCLM3 cells, indicating that Elmo1 expression is involved in cell adhesion to the extracellular matrix (Fig. 3D). Up-regulation of Elmol expression may be involved in the invasive phenotype of HCC cells by promoting cell migration and adhesion (23).

\section{Discussion}

Management of metastasis contributes to an improvement in the prognosis of HCC patients. The development of cancer such as HCC is characterized by multi-step processes associated with alterations in the expression of genes involved in cell proliferation, invasion and metastasis (24). Previous findings indicate that invasion and metastasis are, to a large extent, attributable to the ability of cells to migrate (25).

In a previous study, the association between Dock180 and Elmo1 was confirmed by immunoprecipitation experiments. The results showed that Dock180 interacted predominantly with Crk1, and that inhibition of endogenous Dock180 expression attenuated the invasive behavior of SKOV3 cell lines concomitant with a reduction in activated Rac1, which is a key regulator of actin cytoskeletal dynamics modulating cell migration and invasion (26). However, the role of Elmo1 in human HCC remains unknown. Thus, the present study aimed to investigate the role of Elmol in HCC. Elmo1 mRNA and protein expression was assessed in HCC tissues, and the expression levels of Elmol mRNA and protein were found to be significantly higher in HCC tissues than in the corresponding ANTTs. These results were consistent with a previous study in gliomas and ovarian cancer cell lines, which also suggested that the Elmol gene may play an important role in invasion and metastasis (21).

In the present study, levels of Elmol mRNA and protein in HCC tissues as determined by qRT-PCR and Western blot analysis were investigated for a correlation with clinicopathological features of HCC. The expression of Elmol mRNA and protein was significantly correlated with vein invasion and the Edmondson-Steiner grade of the HCC tissues. Substantial evidence indicates that vein invasion and angiogenesis are highly correlated with invasion and metastasis, as well as with the prognosis of HCC. Consistent with these results, a highly significantly association was noted between the Elmol expression level and prognosis/metastasis of HCC. Multivariate Cox regression analyses indicated that Elmo1 expression was an independent risk factor for the prognosis of HCC patients, in addition to Edmondson-Steiner grade and venous invasion. These results suggest that Elmol may play a key role in HCC development.

These findings were confirmed in three HCC cell lines with different spontaneous metastatic potential. HepG2 cells exhibit a moderate metastatic potential, whereas HCCLM3 cells show highly invasive potential, as indicated by extensive metastases via orthotopic inoculation (27). Based on this difference in metastatic potential, this cell model system may serve as a useful platform for the study of HCC metastasis. The protein expression of Elmol was previously found to be 
significantly higher in the HCCLM3 cell line compared to the HepG2 cell line (28) as verified in our study. To evaluate the role of Elmol expression in regulating cell migration in $\mathrm{HCC}$, the HCCLM3 cell line was treated with Elmol siRNA, which successfully blocked Elmol expression. The results indicate that Elmol regulates cell migration in $\mathrm{HCC}$ cells, and that increased expression of Elmol is associated with the metastatic potential of HCC.

In the present study, we demonstrated that the knockdown of Elmol was associated with the inhibition of invasion and the migration of HCCLM3 cells, consistent with the critical role of Elmo1 in the control of cellular motility. Thus, Elmo1 may serve as a possible powerful therapeutic target for metastatic HCC.

\section{References}

1. He J, Gu D, Wu X, Reynolds K, Duan X, Yao C, Wang J, Chen CS, Chen J, Wildman RP, Klag MJ and Whelton PK: Major causes of death among men and women in China. N Engl J Med 353: 1124-1134, 2005.

2. Fan ST, Lo CM, Liu CL, Lam CM, Yuen WK, Yeung C and Wong J: Hepatectomy for hepatocellular carcinoma: toward zero hospital death. Ann Surg 229: 322-330, 1999.

3. Hubert C, Sempoux C, Rahier J, Horsmans Y, Geubel A, van Beers BE, Annet L, Zech F, Leonard D and Gigot JF: Prognostic risk factors of survival after resection of hepatocellular carcinoma. Hepatogastroenterology 54: 1791-1797, 2007.

4. Ibrahim S, Roychowdhury A and Hean TK: Risk factors for intrahepatic recurrence after hepatectomy for hepatocellular carcinoma. Am J Surg 194: 17-22, 2007.

5. Mann CD, Neal CP, Garcea G, Manson MM, Dennison AR and Berry DP: Prognostic molecular markers in hepatocellular carcinoma: a systematic review. Eur J Cancer 43: 979-992, 2007.

6. Murray CJ and Lopez AD: Mortality by cause for eight regions of the world: global burden of disease study. Lancet 349: 1269-1276, 1997.

7. Giannelli G and Antonaci S: Novel concepts in hepatocellular carcinoma: from molecular research to clinical practice. J Clin Gastroenterol 40: 842-846, 2006.

8. Yang LY, Tao YM, Ou DP, Wang W, Chang ZG and Wu F: Increased expression of Wiskott-Aldrich syndrome protein family verprolin-homologous protein 2 correlated with poor prognosis of hepatocellular carcinoma. Clin Cancer Res 12: 5673-5679, 2006.

9. Farinati F, Rinaldi M, Gianni S and Naccarato R: How should patients with hepatocellular carcinoma be staged? Validation of a new prognostic system. Cancer 89: 2266-2273, 2000.

10. Wong CC, Wong CM, Au SL and Ng IO: RhoGTPases and Rho-effectors in hepatocellular carcinoma metastasis: ROCK N'Rho move it. Liver Int 30: 642-656, 2010.

11. Chae S, Jun HO, Lee EG, Yang SJ, Lee DC, Jung JK, Park KC, Yeom YI and Kim KW: Osteopontin splice variants differentially modulate the migratory activity of hepatocellular carcinoma cell lines. Int J Oncol 35: 1409-1416, 2009.

12. Feng H, Zhang J, Li X and Chen WN: HBX-mediated migration of HBV-replicating HepG2 cells: insights on development of hepatocellular carcinoma. J Biomed Biotechnol: Sep. 16, 2009 (Epub ahead of print)
13. Grise F, Bidaud A and Moreau V: Rho GTPases in hepatocellular carcinoma. Biochim Biophys Acta 1795: 137-151, 2009.

14. Fukui K, Tamura S, Wada A, Kamada Y, Sawai Y, Imanaka K, Kudara T, Shimomura I and Hayashi N: Expression and prognostic role of RhoA GTPases in hepatocellular carcinoma. J Cancer Res Clin Oncol 132: 627-633, 2006.

15. Carmona-Cuenca I, Roncero C, Sancho P, Caja L, Fausto N and Fernández M: Upregulation of the NADPH oxidase NOX4 by TGF-beta in hepatocytes is required for its pro-apoptotic activity. J Hepatol 49: 965-976, 2008.

16. Lee TK, Poon RT, Yuen AP, Man K, Yang ZF, Guan XY and Fan ST: Significance of the Rac signaling pathway in HCC cell motility: implications for a new therapeutic target. Carcinogenesis 26: 681-687, 2005.

17. Hiramoto K, Negishi M and Katoh H: Dock4 is regulated by RhoG and promotes Rac-dependent cell migration. Exp Cell Res 312: 4205-4216, 2006.

18. Epting D, Wendik B, Bennewitz K, Dietz CT, Driever W and Kroll J: The Rac1 regulator ELMO1 controls vascular morphogenesis in zebrafish. Circ Res 107: 45-55, 2010

19. Hope H, Schmauch C, Arkowitz RA and Bassilana M: The Candida albicans ELMO homologue functions together with Rac1 and Dck1, upstream of the MAP Kinase Cek1, in invasive filamentous growth. Mol Microbiol 76: 1572-1590, 2007.

20. Komander D, Patel M, Laurin M, Fradet N, Pelletier A and Barford D: An alpha-helical extension of the ELMO1 pleckstrin homology domain mediates direct interaction to DOCK180 and is critical in Rac signaling. Mol Biol Cell 19: 483748-483751, 2008.

21. Bouschet T, Martin S, Kanamarlapudi V, Mundell S and Henley JM: The calcium-sensing receptor changes cell shape via a beta-arrestin-1 ARNO ARF 6 ELMO protein network. J Cell Sci 120: 2489-2497, 2007.

22. Ip WK, Lai PB, Wong NL, Sy SM, Beheshti B, Squire JA and Wong N: Identification of PEG10 as a progression related biomarker for hepatocellular carcinoma. Cancer Lett 250: 284-291, 2007.

23. Shimazaki A, Tanaka Y, Shinosaki T, Ikeda M, Watada H, Hirose T, Kawamori $\mathrm{R}$ and Maeda S: ELMO1 increases expression of extracellular matrix proteins and inhibits cell adhesion to ECMs. Kidney Int 70: 1769-1776, 2006.

24. Jarzynka MJ, Hu B, Hui KM, Bar-Joseph I, Gu W, Hirose T, Haney LB, Ravichandran KS, Nishikawa R and Cheng SY: ELMO1 and Dock180, a bipartite Rac1 guanine nucleotide exchange factor, promote human glioma cell invasion. Cancer Res 67: 7203-7211, 2007.

25. Hsu SC, Kuo CL, Lin JP, Lee JH, Lin CC, Su CC, Yang MD and Chung JG: Crude extracts of Euchresta formosana radix inhibit invasion and migration of human hepatocellular carcinoma cells. Anticancer Res 27: 2377-2384, 2007.

26. Wong CC, Wong CM, Ko FC, Chan LK, Ching YP and Yam JW: Deleted in liver cancer 1 (DLC1) negatively regulates Rho/ ROCK/MLC pathway in hepatocellular carcinoma. PLoS One 23: E2779, 2008

27. Tian J, Tang ZY, Ye SL, Liu YK, Lin ZY, Chen J and Xue Q: New human hepatocellular carcinoma (HCC) cell line with highly metastatic potential (MHCC97) and its expressions of the factors associated with metastasis. Br J Cancer 81: 814-821, 1999.

28. Zhang SZ, Pan FY, Xu JF, Yuan J, Guo SY, Dai G, Xue B, Shen WG, Wen CJ, Zhao DH and Li CJ: Knockdown of c-Met by adenovirus-delivered small interfering RNA inhibits hepatocellular carcinoma growth in vitro and in vivo. Mol Cancer Ther 4: 1577-1584, 2005. 